\title{
Cost Optimization of Absorption Capture Process
}

\author{
Cemil Sahin Lars Erik $\varnothing_{\mathrm{i}}$ \\ Department of and Process, Energy and Environmental Technology, \\ University College of Southeast Norway, Norway, lars.oi@usn. no
}

\begin{abstract}
In this work, a $\mathrm{CO}_{2}$ absorption process using aqueous monoethanol amine (MEA) as solvent for a post combustion capture plant was simulated using Aspen HYSYS. An Aspen HYSYS spreadsheet was used for equipment dimensioning, cost estimation and cost optimization. A standard process and a vapor recompression process for $85 \% \mathrm{CO}_{2}$ removal were simulated using the Li-Mather thermodynamic model. The energy consumptions and the total cost were calculated and compared. Cost optimum process parameters were calculated from sensitivity analysis. The vapor recompression process was shown to be both energy and cost optimum. With 20 years calculation period, the cost optimum absorber packing height was 16 meter, optimum temperature approach was $14 \mathrm{~K}$ and optimum recompression pressure was $130 \mathrm{kPa}$. With 10 years calculation period, the optimum values for the same parameters were 16 meter, $17 \mathrm{~K}$ and $140 \mathrm{kPa}$. Calculations of optimum process parameters dependent on factors like the calculation period have not been found in literature. Except from the temperature approach, the optimum values varied only slightly when the calculation period was changed.
\end{abstract}

Keywords: $\mathrm{CO}_{2}$, amine, absorption, cost estimation, Aspen HYSYS

\section{Introduction}

$\mathrm{CO}_{2}$ absorption with aqueous monoethanol amine (MEA) as solvent is well-known and mature for large scale post combustion $\mathrm{CO}_{2}$ capture. This process has a high energy consumption. There have been suggested many modifications to reduce the heat demand for the reboiler in the desorption column. Vapor recompression is one of the simplest way to reduce the energy need (Øi et al., 2014). In this paper, the standard and vapor recompression configuration were simulated, cost estimated and optimized using the process simulation program Aspen HYSYS. The results in this work are mainly from a Master Thesis work (Sahin, 2016).

The economic performance of a $\mathrm{CO}_{2}$ removal process plant has been evaluated in earlier work (AbuZahra et al., 2007). The amine concentration, lean amine loading and desorber column pressure was determined to be the main factors influencing on the cost. The capital cost and energy consumption of different configurations have been evaluated using the Unisim and ProTreat simulation programs (Karimi et al., 2011). One reference (Fernandez et al., 2012) has performed cost estimation and found optimum cost parameters using rate based Aspen Plus simulation. Another reference (Cousins et al., 2011) simulated different configurations using Aspen Plus and compared the energy consumption.

There is very limited published work on cost optimum parameters, cost evaluation and optimization of alternative configurations. At University College of Southeast Norway, different modification alternatives were simulated and cost estimated using Aspen HYSYS (Øi et al., 2014). The cost optimum absorber packing height, the minimum temperature approach in the main heat exchanger and the gas inlet temperature were calculated for the standard process using Aspen HYSYS (Øi, 2012; Kallevik, 2010).

The aim of this work is to simulate and cost estimate the standard $\mathrm{CO}_{2}$ absorption process and the vapor recompression process. Then different parameters are varied to energy optimize and cost optimize different process parameters and the total process. A special aim in this work is to vary cost factors, and especially the calculation period between 10 and 20 years to evaluate the effect on the optimum parameters.

\section{Process description}

\subsection{Principles of Standard Process}

The standard amine based $\mathrm{CO}_{2}$ capture process contains an absorber, a stripper with reboiler and condenser, a lean/rich heat exchanger, pumps and a lean amine cooler as shown in Figure 1.

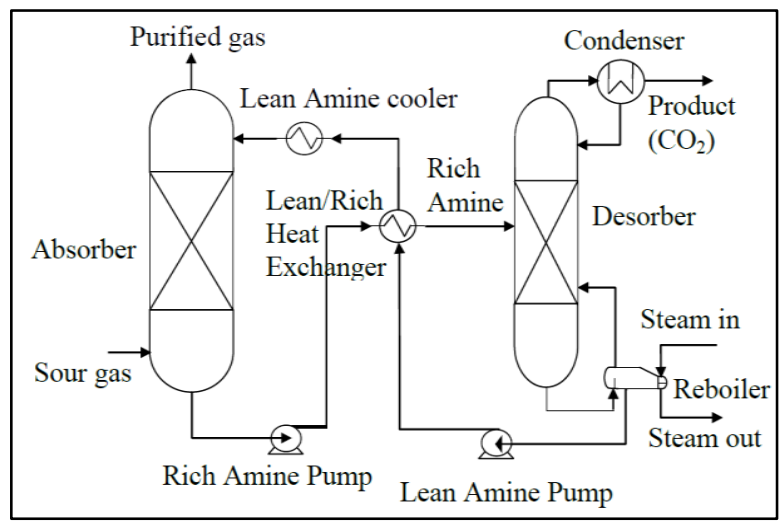

Figure 1. Principle for standard amine based $\mathrm{CO}_{2}$ capture process (Aromada and Øi, 2015). 
When the flue gas rises from the bottom to the top of the absorption column, $\mathrm{CO}_{2}$ is absorbed by the solvent. The rich amine is pumped from the absorption column to the desorber column passing through the lean/rich heat exchanger. In the stripper, the absorbed $\mathrm{CO}_{2}$ is removed from the solvent using thermal energy supplied to the reboiler. The lean amine from the bottom of desorber is pumped to the absorption column via the lean/rich heat exchanger and the lean amine cooler.

\subsection{Principles of Vapor Recompression}

The principles of vapor recompression are shown in Figure 2. The difference from the standard process is that the regenerated amine solution from the desorber is flashed using a valve and led to a two-phase separator. The liquid from the separator is returned back to the absorber. The vapor from the separator is compressed and sent back to the bottom of the desorber.

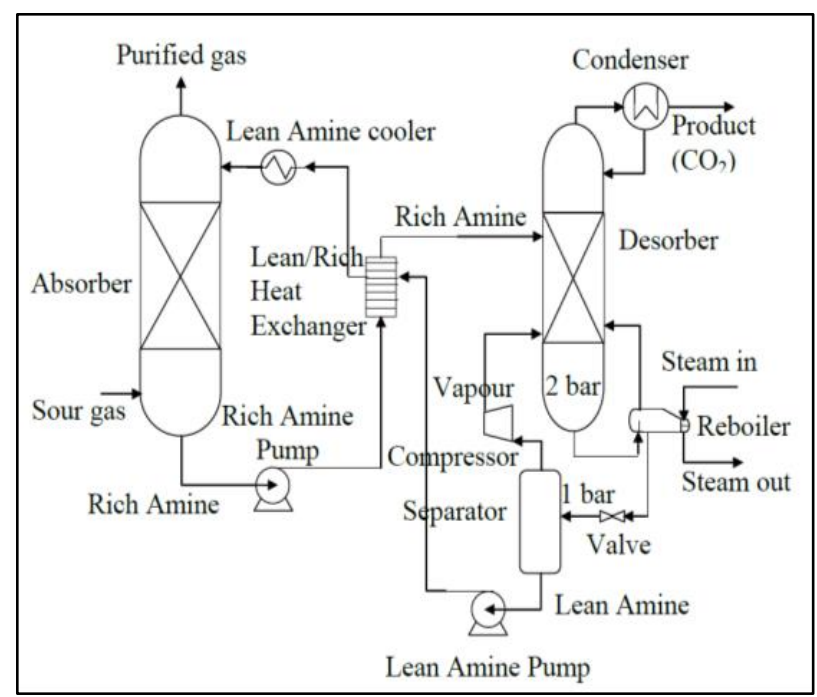

Figure 2. Principle for vapor recompression process (Aromada and Øi, 2015).

\section{Models}

\subsection{Equilibrium Models}

The Kent-Eisenberg (Kent and Eisenberg, 1976) and the Li-Mather ( $\mathrm{Li}$ and Mather, 1996) vapor/liquid equilibrium models are available models in the Amine Property Package in Aspen HYSYS. Both models are quite complex involving several adjusted parameters. The Kent-Eisenberg model is claimed to give faster convergence while the Li-Mather model is claimed to be more robust (Øi et al., 2014). The non-ideal vapor phase model is used in the simulations in this work.

\subsection{Column Models and Iteration Algorithms}

Equilibrium stages are used to model the columns. A certain packing height can be modelled as an equilibrium stage. One equilibrium stage can be calculated with the assumption that there is equilibrium between the $\mathrm{CO}_{2}$ concentration in the gas and liquid leaving the stage. A Murphree efficiency can be used to model deviation from equilibrium. It can be specified explicitly for each stage in a column in Aspen HYSYS (Øi, 2007). The Modified HYSIM Inside-Out algorithm with adaptive damping is specified for the columns. This is also done in earlier simulations (Øi, 2007).

\section{Process Simulations}

\subsection{Specifications for Standard $\mathrm{CO}_{2}$ Capture Process}

The standard $\mathrm{CO}_{2}$ removal process has been simulated in Aspen HYSYS with the specifications in Table 1. The Aspen HYSYS process flow diagram is shown Figure 3. The specifications are based on earlier works with amine absorption from a natural gas based power plant by Øi (2007). The amine package with the Li-Mather model was used in all the simulations in this work.

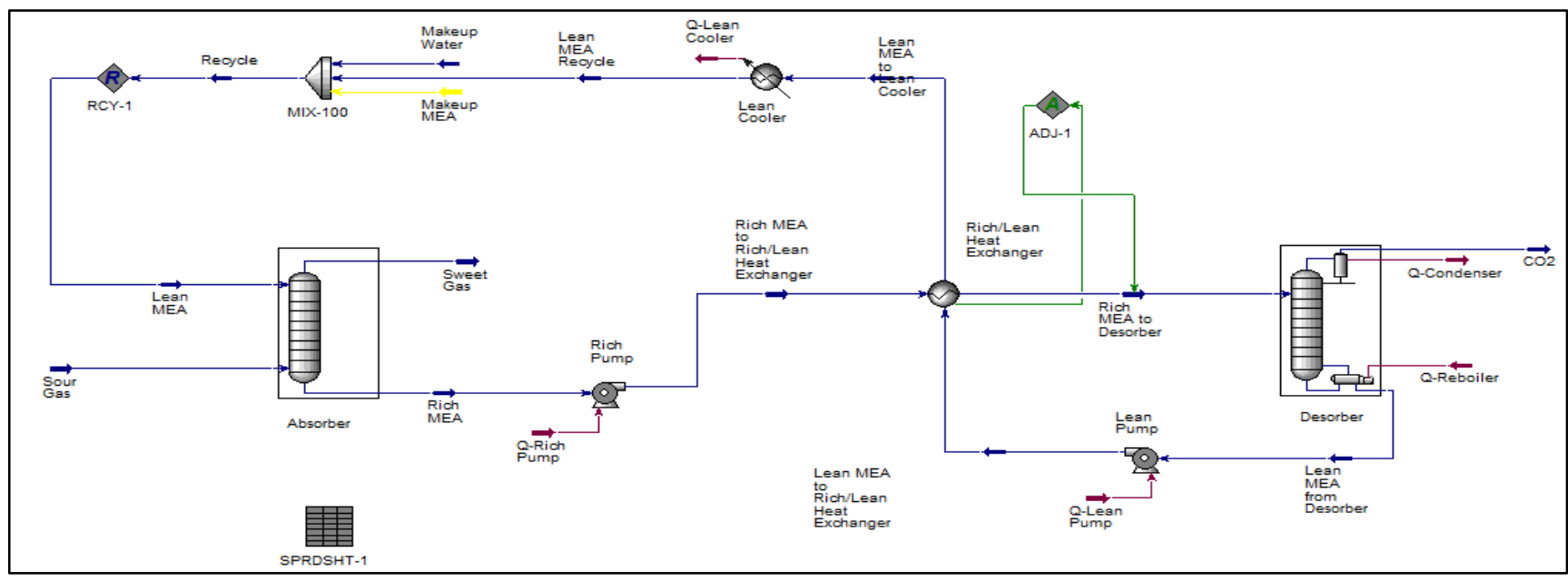

Figure 3. Aspen HYSYS flow-sheet for standard $\mathrm{CO}_{2}$ capture process. 
Table 1. Specifications for standard process.

\begin{tabular}{|l|l|l|}
\hline Parameter & Unit & Value \\
\hline $\mathrm{CO}_{2}$ removal grade & mass $\%$ & 85 \\
\hline Inlet gas temperature & ${ }^{\circ} \mathrm{C}$ & 40 \\
\hline Inlet gas pressure & $\mathrm{kPa}$ & 110 \\
\hline Inlet gas flow rate & $\mathrm{kmol} / \mathrm{h}$ & 85000 \\
\hline $\mathrm{CO}_{2}$ in inlet gas & $\mathrm{mole} \%$ & 3.73 \\
\hline Water in inlet gas & $\mathrm{mole} \%$ & 6.71 \\
\hline Nitrogen in inlet gas & $\mathrm{mole} \%$ & 89.56 \\
\hline Lean amine temperature & ${ }^{\circ} \mathrm{C}$ & 40 \\
\hline Lean amine pressure & $\mathrm{kPa}$ & 101 \\
\hline Lean amine rate & $\mathrm{kmol} / \mathrm{h}$ & 128000 \\
\hline MEA content in lean amine & $\mathrm{mass} \%$ & 29 \\
\hline $\mathrm{CO}_{2}$ content in lean amine & $\mathrm{mass} \%$ & 5.5 \\
\hline Number of stages in absorber & - & 16 \\
\hline Murphree efficiency in absorber & - & 0.15 \\
\hline Rich amine pump pressure & $\mathrm{kPa}$ & 200 \\
\hline Rich amine temperature to desorber & ${ }^{\circ} \mathrm{C}$ & 104.5 \\
\hline Number of stages in desorber & - & $8(2+6)$ \\
\hline Murphree efficiency in desorber & - & 1 \\
\hline Reflux ratio in stripper & - & 0.3 \\
\hline Reboiler temperature & ${ }^{\circ} \mathrm{C}$ & 120 \\
\hline Minimum $\Delta \mathrm{T}$ in Rich/Lean $\mathrm{HX}$ & ${ }^{\circ} \mathrm{C}$ & 10 \\
\hline & & \\
\hline
\end{tabular}

The heat consumption in the reboiler was calculated to $3.72 \mathrm{MJ} / \mathrm{kg} \mathrm{CO}_{2}$ which is slightly higher than in some references (Karimi et al., 2011; Fernandez et al., 2012; $\left.\varnothing_{i}, 2007\right)$ but lower than in some other references
(Cousins et al., 2011; Øi and Vozniuk, 2010). The range in these references are from 3.56 to $3.80 \mathrm{MJ} / \mathrm{kg}$.

\subsection{Simulation of Vapor Recompression}

A simulation of the vapor recompression process was performed. The Aspen HYSYS flow diagram is in Figure 4. The flash pressure was specified to $120 \mathrm{kPa}$ and the efficiency of the compressor was defined to 75 $\%$. To achieve $85 \% \mathrm{CO}_{2}$ removal efficiency, the lean amine flow rate was adjusted to $111000 \mathrm{kmol} / \mathrm{h}$ and the resulting lean amine $\mathrm{CO}_{2}$ concentration was 5.12 mass $\%$. The rich amine temperature to the desorber was adjusted to $95.8^{\circ} \mathrm{C}$ to achieve the minimum temperature approach as $10^{\circ} \mathrm{C}$ in the heat exchangers.

With the vapor recompression modification the reboiler heat consumption was reduced from $3.72 \mathrm{MJ} / \mathrm{kg}$ to $3.02 \mathrm{MJ} / \mathrm{kg}$. In literature the calculated reboiler heat consumption was 3.03 and $3.04 \mathrm{MJ} / \mathrm{kg}$ (Fernandez et al., 2012; Cousins et al., 2011).

The equivalent heat consumption was calculated to $3.28 \mathrm{MJ} / \mathrm{kg}$ using a conversion efficiency from reboiler heat (low pressure steam) to electricity as $25 \%$. The equivalent heat consumption was calculated in literature to $3.30 \mathrm{MJ} / \mathrm{kg}$ (Fernandez et al., 2012).

\subsection{Dimensioning and Cost Estimation}

The absorption and desorption column diameters were calculated based on gas velocities of $2 \mathrm{~m} / \mathrm{s}$ and $1 \mathrm{~m} / \mathrm{s}$ respectively. The packing height was determined with the assumption of 1 meter structured packing for each stage. The column height in addition to packing was 24 $\mathrm{m}$ for the absorber and $20 \mathrm{~m}$ for the desorber. The pressure drop for each stage in the absorber was $900 \mathrm{~Pa}$.

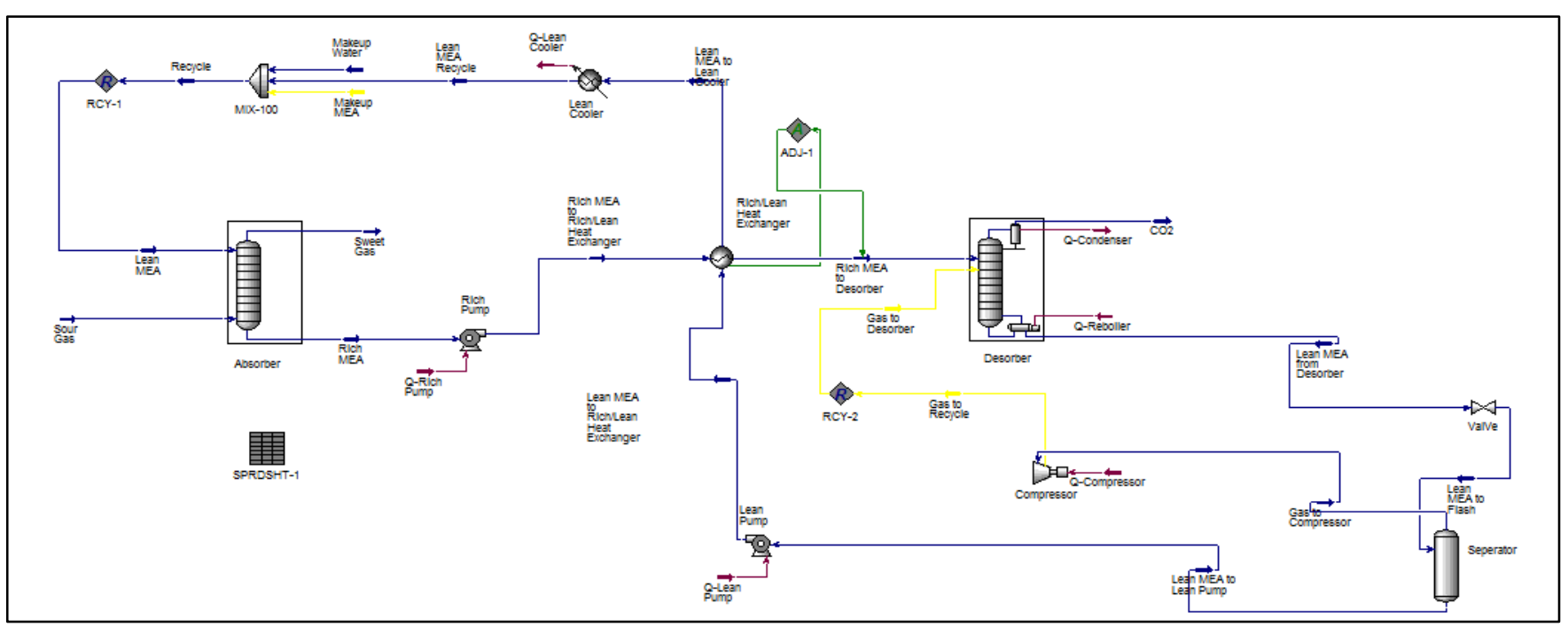

Figure 4. Aspen HYSYS flow-sheet for vapor recompression process. 
The heat exchangers were specified as plate heat exchanger. The overall heat transfer coefficients were calculated for the lean/rich heat exchanger and lean amine cooler and estimated to $2500 \mathrm{~W} / \mathrm{m}^{2} \mathrm{~K}$ for the reboiler and the condenser. Pumps and compressors were specified with $75 \%$ adiabatic efficiency.

The operating cost was mainly estimated from the energy cost. The maintenance cost was specified as $5 \%$ of the capital cost. The rate of currency was 1 USD to 8.6 NOK. The electricity cost and the steam cost was specified to 0.62 and $0.155 \mathrm{NOK} / \mathrm{kWh}$ based on a conversion efficiency from low pressure steam to electricity of $25 \%$. Operating time per year was defined to 8000 hours. The calculation period was 20 years and the rate of interest was $7 \%$.

Open source internet cost estimation calculators, one is based on data from Peters and Timmerhaus, were used to calculate the equipment cost (Milligan and Milligan, 2014; Peters et al., 2002). Outside the range of equipment size, power law exponents of $0.57,1.0,0.55$, 0.28 and 0.95 were used for column vessels, packing, heat exchangers, pumps and compressors. The Chemical Engineering Plant Cost Index was used to convert to USD (2015). After finding the equipment cost, the installed equipment cost was calculated using the detailed factor method using factors for engineering cost, administration cost and contingency.

The net present value using the operating and total installed cost was calculated to 3810 MNOK for the standard process and 3540 MNOK for the vapor recompression process.

\section{Cost Optimization}

After concluding that the vapor recompression process was more cost optimum than the standard process, the net present value was calculated with varying conditions to find the optimum parameters for the vapor recompression process.

\subsection{Cost Optimization of Minimum Temperature Approach}

The trade-off was performed with varying minimum approach temperature in the lean/rich heat exchanger. The heat exchanger area and the steam consumption in the reboiler were the main affected variables. The energy consumption and cost optimum as a function of minimum approach temperature is shown in Figure 5.

The calculated optimum value was $14^{\circ} \mathrm{C}$ with the net present value of 3490 MNOK. As the minimum approach temperature increased, the operational cost increased and the investment cost decreased continuously. Similar calculations were performed for a reduced calculation period of 10 years. The cost optimum temperature approach is shown in Figure 6. The optimum value was $17^{\circ} \mathrm{C}$ with a net present value of $2710 \mathrm{MNOK}$. The reason for the higher value is that the investment cost dominates more than the operational cost as the calculation period decrease.

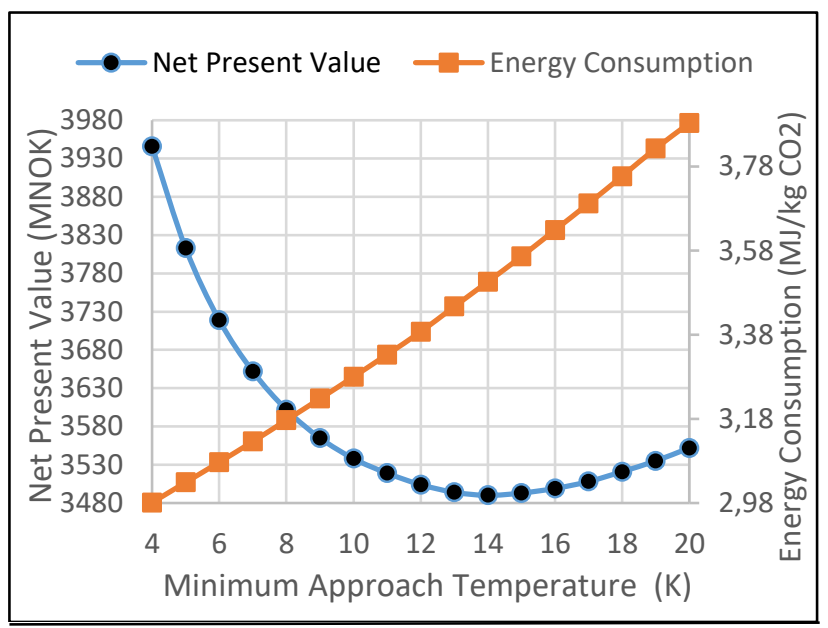

Figure 5. Net present value and energy consumption as a function of minimum temperature approach in heat exchanger for 20 years calculation period.

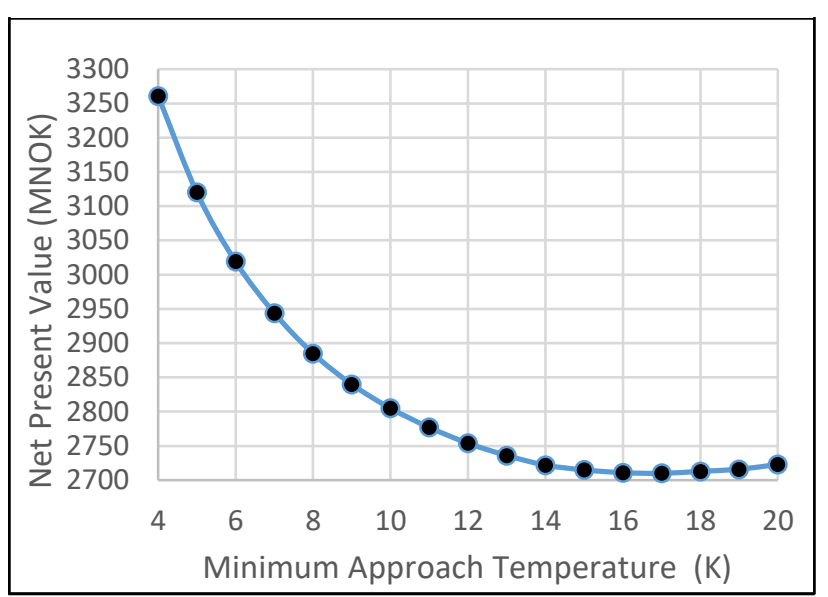

Figure 6. Net present value and energy consumption as a function of minimum temperature approach in heat exchanger for 10 years calculation period.

The cost optimum temperature approach is comparable to values found in literature. Comparisons of optimum temperature approach for different calculation periods have however not been found in literature. The optimum was calculated to $12^{\circ} \mathrm{C}$ for the calculation period of 15 years and the discount rate of $10.5 \%$ (Øi et al., 2014) and to $19^{\circ} \mathrm{C}$ for the calculation period of 10 years and an interest rate of $7 \%$ (Øi, 2012). 


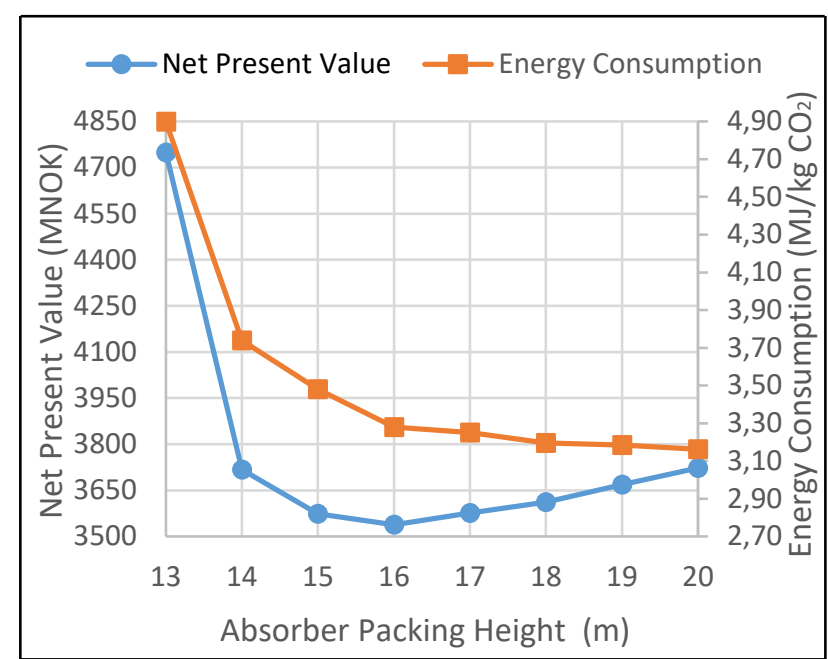

Figure 7. Net present value and energy consumption as a function of absorber packing height for 20 years.

\subsection{Cost Optimisation of Absorber Packing Height}

The number of absorber stages equivalent to 1 meter was varied between 13 and 20 . The cost optimum value of 3540 MNOK was achieved with 16 stages as shown in Figure 7. As the number of stages increased, the necessary amine flow rate to keep the $85 \% \mathrm{CO}_{2}$ removal efficiency decreased. The equivalent heat consumption decreased from $4.9 \mathrm{MJ} / \mathrm{kg} \mathrm{CO}$ at 13 stages to 3.16 $\mathrm{MJ} / \mathrm{kg} \mathrm{CO} 2$ at 20 stages. The investment of the absorber column, the amine heat exchanger, the compressor, the electric consumption due to fan and compressor and steam consumption in the reboiler were the major changes. For 10 years calculation period, the cost optimum value was also achieved with 16 stages as shown in Figure 8.

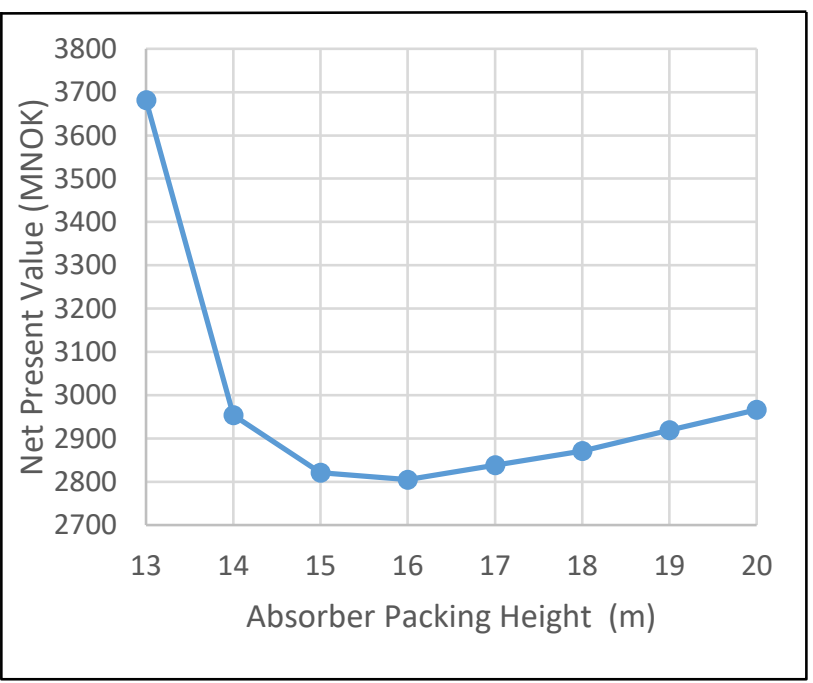

Figure 8. Net present value and energy consumption as a function of absorber packing height for 20 years.
Similar values are found in literature. For the calculation period of 15 years, 16 stages in the absorption column was calculated as the cost optimum value (Øi et al, 2014). In another optimization calculation, the optimum value was also 16 stages for a calculation period of 10 years $(\varnothing \mathrm{i}, 2012)$. Evaluations of the influence of the calculation period on the optimum packing height have not been found in literature.

\subsection{Cost Optimization of Flash Pressure}

The flash pressure (pressure before recompression) can be varied. The cost of the lean/rich heat exchanger, the compressor, the reboiler and the energy consumption in the compressor and the reboiler changed when the flash pressure was varied. The equivalent heat consumption was reduced to $3.27 \mathrm{MJ} / \mathrm{kg} \mathrm{CO}_{2}$ at 1.1 bar. The cost optimum pressure was calculated to be 1.3 bar with a net present value of $3530 \mathrm{MNOK}$. The result of the cost optimum flash pressure is given in Figure 9. The cost optimum flash pressure is slightly different from the energy optimum value. The reason is that the energy saving is dominated by the investment cost of the compressor until 1.3 bar.

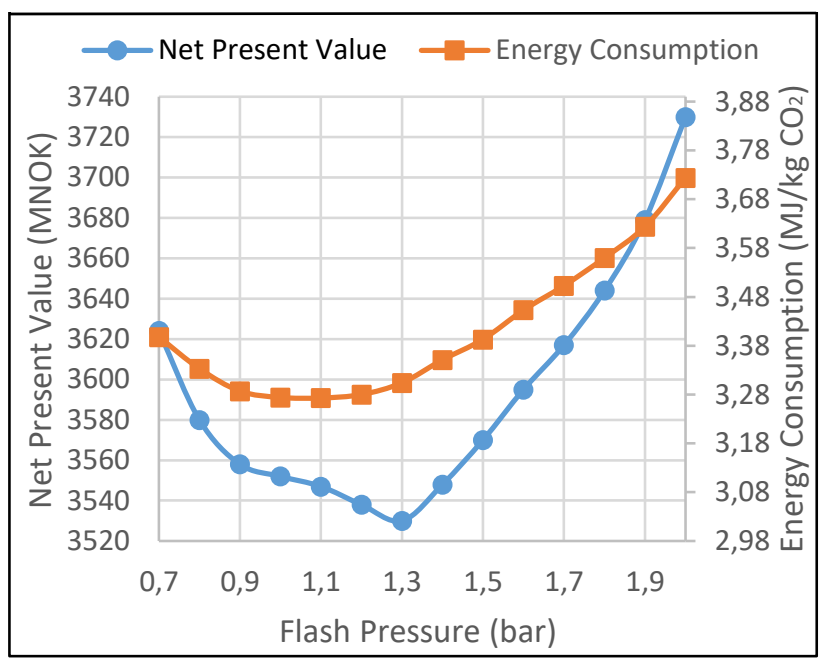

Figure 9. Net present value and energy consumption as a function of flash pressure for 20 years.

For a calculation period of 10 years, the cost optimum flash pressure was calculated to be 1.4 bar as shown in Figure 10. The dependency of the optimum flash pressure on the calculation period is not obvious. It is however reasonable that as the calculation period increases, the optimum value will intend to decrease because the operational cost becomes more dominant.

In literature, energy optimum flash pressures have been calculated to 1.12 and 1.17 bar (Karimi et al., 2011). In Fernandez et al. (2012), the cost optimum flash pressure was calculated to $1.2 \mathrm{bar}$. The cost optimum 
pressure is slightly higher than the energy optimum because the change in compressor cost is significant. Calculations of optimum flash pressure dependent on factors like the calculation period have not been found in literature.

\subsection{Evaluation of Uncertainty}

The calculations of the equilibriums, the material balances and the energy consumptions in the process simulations are regarded to be reasonable accurate. As a result of this, the deviation in calculated energy consumptions compared to values found in literature is quite low.

The uncertainties in cost estimation of the equipment are much larger. First, there are uncertainties in the dimensioning of the process equipment. Then there is a high uncertainty in the cost of especially heat exchangers and the absorption columns. And the installation cost of all types of equipment also have high uncertainty. The chosen calculation period and chosen discount rate will also influence on the total cost estimate.

The main aim in this paper was to find cost optimum process parameters. It is of interest to find out whether these optimums are dependent on the choice of different cost factors. When comparing optimum parameters calculated in this work compared to values found in literature, the deviation is rather low.

In this paper, optimum parameters have been calculated for a calculation period of 10 and 20 years. The differences in calculated optimums are very small. The only deviation was in the optimum temperature difference approach in the main heat exchanger that changed slightly from 14 to $17^{\circ} \mathrm{C}$.

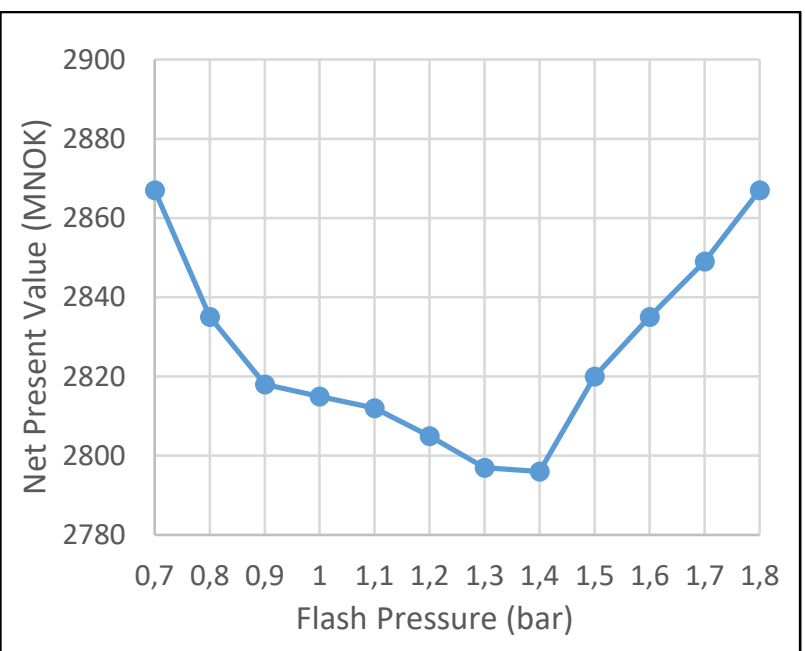

Figure 10. Net present value as a function of flash pressure for 10 years.

\section{Conclusions}

Simulations and optimizations of an amine-based $\mathrm{CO}_{2}$ removal process were performed in the search for a cost optimum process. The process configurations examined were a standard process and a vapor recompression process. The energy consumptions and the total cost were calculated and compared.

The vapor recompression modification gave lower total cost compared to a standard process. Optimizations of parameters like minimum temperature approach, height of absorber packing and flash pressure were performed. Cost optimum process parameters were calculated from sensitivity analysis.

Calculations of optimum process parameters dependent on factors like the calculation period have not been found in literature. With 20 years calculation period, the cost optimum absorber height was 16 meter, optimum temperature approach was $14 \mathrm{~K}$ and optimum recompression pressure was $130 \mathrm{kPa}$. With 10 years calculation period, the optimum values for the same parameters were 16 meter, $17 \mathrm{~K}$ and $140 \mathrm{kPa}$. Except for the minimum temperature approach, it seems like when varying different cost factors like the calculation period, the cost optimum values vary only slightly.

\section{References}

M. R. M. Abu-Zahra, J. P. M. Niederer, P.H.M. Feron and G. F. Versteeg. $\mathrm{CO}_{2}$ capture from power plants: Part II. A parametric study of the economical performance based on mono-ethanolamine. International Journal of Greenhouse Gas Control, 1:135-142, 2007.

S. A. Aromada and L. E. Øi. Simulation of Improved Absorption Configurations for $\mathrm{CO}_{2}$ Capture. In Linköping Electronic Conference Proceedings from SIMS 56, pages 21-29, 2015.

A. Cousins, L. T. Wardhaugh and P. H. M. Feron. Preliminary analysis of process flow sheet modifications for energy efficient $\mathrm{CO}_{2}$ capture from flue gases using chemical absorption. Chemical Engineering Research and Design, 89:1237-1251, 2011.

E. S. Fernandez, E. J. Bergsma, F. de Miguel Mercader, E. L.V. Goetheer and T. J. H. Vlugt. Optimisation of lean vapour compression LVC as an OPTION for post-combustion $\mathrm{CO}_{2}$ capture: Net present value maximisation. International Journal of Greenhouse Gas Control, 11:114-121, 2012. doi: http://dx.doi.org/10.1016/j.ijggc.2012.09.007

O. B. Kallevik. Cost estimation of $\mathrm{CO}_{2}$ removal in HYSYS. Master Thesis, Telemark University College, Porsgrunn, Norway, 2010.

M. Karimi, M. Hillestad and H. F. Svendsen. Capital costs and energy considerations of different alternative stripper configurations for post combustion $\mathrm{CO}_{2}$ capture. Chemical Engineering Research and Design, 89:1229-1236, 2011.

R. L. Kent and B. Eisenberg. Better data for amine treating. Hydrocarbon processing, 55(2):87-90, 1976.

Y. Li and A. E. Mather. Correlation and prediction of the solubility of $\mathrm{CO}_{2}$ and $\mathrm{H}_{2} \mathrm{~S}$ in aqueous solutions of triethanolamine. Industrial \& Engineering Chemistry Research, 35:4804-4809, 1996. 
D. A. Milligan and J. A. Milligan. Internet cost estimation program. $2014 . \quad$ Available (06.02.2016): http://www.matche.com/equipcost/Default.html

M. S. Peters, K.D. Timmerhaus and R. E. West. Internet cost estimation program. 2002. Available (01.02.2016): http://www.mhhe.com/engcs/chemical/peters/data/

C. Sahin. Optimization of $\mathrm{CO}_{2}$ capture based on cost estimation. Master Thesis, University College of Southeast Norway, 2016.

L. E. Øi. Aspen HYSYS simulation of $\mathrm{CO}_{2}$ removal by amine absorption from a gas based power plant. In The 48th Scandinavian Conference on Simulation and Modelling (SIMS2007), Göteborg, Sweden, 2007.

L. E. Øi. Removal of $\mathrm{CO}_{2}$ from exhaust gas. $\mathrm{PhD}$ Thesis, Telemark University College, Porsgrunn. (TUC 3: 2012)

L. E. Øi, T. Bråthen, C. Berg, S. K. Brekne, M. Flatin, R. Johnsen, I. G. Moen and E. Thomassen. Optimization of configurations for amine based $\mathrm{CO}_{2}$ absorption using Aspen HYSYS. Energy Procedia, 51:224-233, 2014.

L. Øi and I. Vozniuk. Optimizing $\mathrm{CO}_{2}$ absorption using splitstream configuration. In conference proceedings of Processes and Technologies for a Sustainable Energy, Ischia, Italy, 2010. 